\title{
Identidades docentes e diferença no discurso de professores de Língua Inglesa em formação inicial
}

\author{
Ana Paula D. Baladeli \& Clarice Nadir von Borstelii \\ Universidade Estadual do Oeste do Paraná, Brasil \\ Aparecida de Jesus Ferreira \\ Universidade Estadual de Ponta Grossa, Brasil
}

\begin{abstract}
Resumo
Neste artigo discutimos os conceitos de identidades docentes e diferença a partir de um recorte de dados de pesquisa narrativa. A pesquisa foi realizada com um grupo de professores em formação inicial participantes do Programa Institucional de Bolsa de Iniciação à Docência - Pibid. A pesquisa objetivou identificar, nos discursos de seis professores de Língua Inglesa em formação inicial de duas universidades públicas do Paraná, Brasil, quais eram os sentidos que estes sujeitos constroem sobre a profissão professor. Tal análise foi fundamentada nos Novos Estudos do Letramento e nos estudos sobre identidade, enfatizando a influência das trajetórias escolares na construção de suas identidades docentes. Em linhas gerais, foi possível observar nos discursos dos seis professores a relação entre as trajetórias escolares e os sentidos que constroem sobre o que é ser professor de Língua Inglesa. Os discursos indicaram ainda que as identidades docentes estão em permanente negociação e que a participação em programas de formação profissional como o Pibid tem favorecido o processo de reflexão do grupo sobre si mesmo e sobre a profissão professor.
\end{abstract}

Palavras-chave Identidades docentes; Diferença; Pibid; Profissão professor

\section{Introdução}

O discurso desempenha papel central no processo de construção das identidades, isso porque, por meio dele assumimos, refutamos, negociamos e 
hibridizamos diferentes identidades sociais (Botía, Cruz, \& Ruiz, 2005; Danielewicz, 2001; Hall, 2009; Moita Lopes, 2003; Norton, 2000; Silva, 2009), inclusive a identidade docente ou profissional, tema em destaque neste artigo. Devido ao fato de os discursos serem mais do que meros artefatos para a comunicação e a interação entre os sujeitos sociais, os estudos sobre as identidades sociais tomam cada vez mais a materialidade discursiva como um dos caminhos possíveis para o (re)conhecimento e a legitimação dos sentidos construídos socialmente sobre determinado grupo social (Ferreira, 2014; Street, 1995). Nesse sentido, a contribuição dos Novos Estudos do Letramento e dos estudos sobre identidade na educação repousa no fato de considerar a pluralidade de condições de realização dos discursos e também a diversidade no contexto sociocultural como fatores que influenciam a forma como os diferentes grupos sociais utilizam, valorizam e compreendem os discursos em sua materialidade (escrita ou não).

No presente artigo discutimos o processo de (re)construção identitária docente de um grupo de professores em formação inicial, bolsistas do Programa Institucional de Bolsa de Iniciação à Docência (Pibid), programa este que integra demais ações do governo brasileiro no Plano Nacional de Educação. Os sujeitos da pesquisa foram os bolsistas do Pibid nomeados na pesquisa de pibidianos, que socializaram suas trajetórias de vida e escolar, bem como suas percepções sobre a profissão professor por meio da produção de narrativas autobiográficas, entrevistas e questionários. A pesquisa em questão foi realizada com dezassete pibidianos de três universidades públicas no estado do Paraná, Brasil, mas, em razão dos limites deste artigo, discutimos as percepções de seis deles a respeito de suas trajetórias escolares como estudantes de Língua Inglesa. A metodologia da pesquisa narrativa subsidiou-nos na proposição de uma pesquisa aplicada com foco na compreensão da identificação ou não dos pibidianos com as práticas pedagógicas vivenciadas na escola e com suas percepções sobre um/uma bom/boa professor(a) de Língua Inglesa.

A narração das trajetórias escolares, bem como sua ressignificação, podem proporcionar maior compreensão sobre si e sobre as escolhas profissionais de professores em formação inicial, servindo, portanto, como subsídio para a atitude reflexiva e problematizadora acerca da própria história (Bolívar, 2002; Nóvoa, 2013; Telles, 2002). Partindo da premissa de que os 
discursos propagam e sedimentam representações sociais que funcionam como matrizes para a reconstrução de identidades, os sentidos veiculados sobre uma profissão, sobre o que é ser um bom professor ou como se caracteriza uma boa aula, precisam ser compreendidos como sentidos resultantes de um dado tempo e condição de produção. Assim, por essa característica movente, os sentidos não podem ser compreendidos como definitivos, cabendo, portanto, permanentes revisões.

No que se refere à pesquisa narrativa e sua contribuição para a educação, em específico para a área de formação de professores, segundo Clandinin e Connely (2011), "a experiência da narrativa do pesquisador é sempre dual, é sempre o pesquisador vivenciando a experiência e também sendo parte da própria experiência" (p. 120). Assim, o foco da pesquisa foi identificar e compreender como os sentidos construídos sobre si e sobre a profissão professor podem tanto contribuir para a ampliação dos estudos sobre a formação inicial do professor de Língua Inglesa como ilustrar os efeitos que a participação no Pibid tem trazido para a (re)construção das identidades docentes dos pibidianos, sujeitos da pesquisa.

A pesquisa narrativa realizada se soma a outras a respeito da formação do professor de Língua Inglesa, com o diferencial de trazer as percepções de um grupo de bolsistas do Pibid sobre si e suas percepções sobre a profissão professor. As narrativas representam produções culturais e sociais produzidas sob certos conjuntos de valores, crenças e também expectativas de seus autores, em um dado tempo e lugar.

Nessa pesquisa narrativa foram utilizados instrumentos como: observações participantes realizadas durante as reuniões semanais ocorridas nos grupos de Pibid participantes da pesquisa; questionários semiestruturados aplicados para traçar um perfil dos sujeitos da pesquisa; narrativas autobiográficas escritas; e entrevistas orais, registradas em áudio, utilizadas para conhecer as trajetórias de vida, escolares e acadêmicas dos pibidianos. Dessa forma, ao narrarem suas percepções sobre a profissão professor, os pibidianos revelaram, durante a geração de dados, que os discursos provenientes da escola, da família, das políticas públicas, da cultura, da mídia e, sobretudo, da academia têm influenciado em suas percepções sobre a profissão professor (Botía et al., 2005). Pesquisadores como Telles (2002) e Clandinin e Connely (2011) destacam que o exercício de 
narrar histórias, além de resultar em uma prática ontológica, uma vez que estamos sempre contando e (re)memorando nossas trajetórias de vida (escolar ou profissional), pode contribuir também, tanto para a construção de nossas subjetividades, quanto para o reconhecimento de nossos 'eus'.

Este artigo está organizado em quatro seções: na primeira apresentamos a proposta do Pibid e seus objetivos como uma dentre outras políticas públicas do Ministério da Educação do Brasil para a melhoria da qualidade do ensino da educação básica; na segunda, conceituamos identidade e diferença, aspectos fundamentais para a formação do professor; na terceira, discutimos o recorte de dados da pesquisa narrativa; e, por último, traçamos algumas considerações à guisa da conclusão da pesquisa sobre identidade de pibidianos de Língua Inglesa.

\section{A proposta do Pibid para a formação de professores}

A iniciativa do governo brasileiro com a criação do Programa Institucional de Bolsas de Iniciação à Docência (Pibid), financiado pela Coordenação de Aperfeiçoamento de Pessoal do Ensino Superior (CAPES), resulta de uma alternativa recente do Ministério da Educação em decorrência do Plano Nacional da Educação (PNE) de investir na formação de professores. O Pibid atualmente integra as diversas licenciaturas do país por meio da concessão de bolsas a acadêmicos das diversas licenciaturas, coordenadores dos subprojetos e professores supervisores. O programa atua tanto na formação inicial quanto na formação continuada dos professores. Assim, professores que atuam na educação básica e que recebem os pibidianos em suas salas de aula são denominados no programa como supervisores; os professores do ensino superior que coordenam os projetos do Pibid são denominados de coordenadores; os acadêmicos bolsistas das licenciaturas que atuam nas escolas são denominados pibidianos. Nessa configuração, por meio da concessão de bolsas a coordenadores, supervisores e pibidianos, a proposta do Pibid tem sido a de integrar a educação básica com os cursos de formação inicial de professores, a fim de incentivar as novas gerações de professores a atuarem na educação básica e também como uma forma de melhorar a qualidade do ensino. Em linhas gerais, o Pibid funciona por meio de ações integradas de colaboração entre coordenadores, supervisores e pibidianos que desenvolvem práticas 
pedagógicas, materiais de ensino e oficinas para serem realizadas nas turmas da escola dos professores supervisores. Diferente do que costuma ocorrer com as ações de intervenção na escola proporcionadas pelas atividades de estágio curricular supervisionado, em que o acadêmico interage por pouco tempo com a escola, no Pibid a relação que se estabelece entre estes sujeitos pretende ser mais profícua, a fim de que os supervisores assumam também o papel ativo de coformadores daqueles pibidianos que recebem em suas salas de aula.

Depois de frequentes adaptações no formato do Pibid desde sua criação, em 2007, atualmente todas as instituições de ensino superior podem concorrer nos editais de seleção de projetos do Pibid, sendo federais, estaduais, municipais, confessionais, privadas ou outras. Segundo a Portaria n. ${ }^{\circ}$ 096, de 18 de julho de 2013, são objetivos do Pibid:

I - incentivar a formação de docentes em nível superior para a educação básica;

II - contribuir para a valorização do magistério;

III - elevar a qualidade da formação inicial de professores nos cursos de licenciatura, promovendo a integração entre educação superior e educação básica;

IV - inserir os licenciandos no cotidiano de escolas da rede pública de educação, proporcionando-lhes oportunidades de criação e participação em experiências metodológicas, tecnológicas e práticas docentes de caráter inovador e interdisciplinar que busquem a superação de problemas identificados no processo de ensino-aprendizagem;

V - incentivar escolas públicas de educação básica, mobilizando seus professores como co-formadores dos futuros docentes e tornando-as protagonistas nos processos de formação inicial para o magistério;

VI - contribuir para a articulação entre teoria e prática necessárias à formação dos docentes, elevando a qualidade das ações acadêmicas nos cursos de licenciatura;

VII - contribuir para que os estudantes de licenciatura se insiram na cultura escolar do magistério, por meio da apropriação e da reflexão sobre instrumentos, saberes e peculiaridades do trabalho docente (Ministério da Educação, 2013).

O programa tem sido ampliado e os projetos submetidos variam conforme as demandas das regiões, das escolas e também dos interesses por parte das instituições formadoras de professores. Com o investimento nos três grupos (coordenadores, supervisores e pibidianos), espera-se que colaborativamente esses sujeitos possam desenvolver alternativas para 
melhorar a qualidade do ensino na escola e, ao mesmo tempo, proporcionar a aprendizagem da profissão professor.

As identidades docentes assumidas, as concepções de educação e as concepções de ensino de Língua Inglesa e seu ensino no contexto da escola pública refletem em alguma medida nos discursos dos pibidianos e, por conseguinte, refletirão também em suas práticas profissionais e em suas escolhas pedagógicas. Dessa forma, as experiências dos sujeitos da pesquisa como alunos e como pibidianos merecem ser desveladas, não com o propósito de valoração, mas como aspecto nevrálgico para a compreensão das percepções que constroem sobre si e sobre a profissão professor.

A proposta adotada no Pibid de integrar e proporcionar a colaboração universidade-escola evidencia a compreensão de que ambos os espaços (escola e universidade) precisam estar mais articulados e alinhados no que se refere à concepção de educação e ao perfil do professor que pretendem receber e formar. Dessa forma, a proposta de trabalho colaborativo de coordenadores (professores das licenciaturas), pibidianos (acadêmicos das licenciaturas) e professores supervisores (professores da educação básica) engajarem-se e unirem esforço para repensar os processos de ensino e aprendizagem se apresenta inovadora. E, assim, a criação do Pibid se apresenta como uma política pública de formação de professores interessante, uma vez que pressupõe a inserção do futuro professor na realidade escolar de forma, em alguns casos, mais sistemática, regular e contextualizada do que a inserção que ocorre via estágio curricular supervisionado. Por se tratar de um programa relativamente novo, visto que foi apenas a partir de 2010 que os cursos de Letras passaram a submeter projetos nas seleções do Pibid, a publicação de pesquisas sobre o Pibid tem sido cada vez mais necessária para mapear os resultados conquistados com esta política e também para discutir os modelos de formação de professores praticados nas licenciaturas.

$\mathrm{Na}$ sequência, apresentamos os conceitos de identidade que balizaram a pesquisa e discutimos estes conceitos no cenário educacional vigente, marcado pela transitoriedade dos sentidos do que é ser professor de Língua Inglesa à luz dos referenciais adotados. 


\section{Identidade e diferença: alguns conceitos}

A concepção de identidade adotada nesta pesquisa considerou os estudos de Gatti (1996), Pimenta (1998), Dubar (2005) e Hall (2009), para quem a identidade não se apresenta como uma entidade fixa - portanto, não é única -, ou mesmo representa uma escolha, da qual o sujeito possa lançar mão conforme sua vontade. A identidade tem como substrato a história; assim, os sujeitos transitam e não permanecem nas identidades, e isso ocorre porque cabe considerar a efemeridade das construções identitárias no cenário Pós-Moderno, em que as identidades sociais, inclusive a identidade docente, estão situadas discursivamente no campo do devir ou vir a ser. Além disso, compreender a construção das identidades assumidas, negadas, refutadas ou hibridizadas requer considerar as condições objetivas por que se pautam os discursos, as crenças e os valores subjacentes à (re)construção das identidades.

Conforme Hall (2009), a identidade se constrói na relação, no contraste, na aceitação ou refutação do outro, ou seja, identidade e diferença estão subjacentes a este processo de compreensão de si e do outro. Dessa forma, para reconhecer-se como parte de um dado grupo social ou identificarse como um sujeito com certas características, e não com outras, há que se buscar na diferença a referência para essa identificação. Por referência, compreendemos o outro não como modelo, mas como um ponto de partida que funciona como o aspecto seminal das identidades sociais a serem construídas, como um substrato necessário para construir-se a si. Por essa razão, a identidade depende da existência do outro para poder existir (Hall, 2009; Silva, 2009). Se a identidade é (re)construída a partir da existência do outro, tal acontece também, por exemplo, com a definição de um bom professor, dado que só podemos conceituar a partir de uma referência do que não seja um bom professor ou das características que um bom professor precisa ter em oposição ao mau professor. Segundo Silva (2009), identidade e diferença refletem uma relação social:

A afirmação da identidade e a enunciação da diferença traduzem o desejo dos diferentes grupos sociais, assimetricamente situados, de garantir o acesso privilegiado aos bens sociais. A identidade e a diferença estão, pois, em estreita conexão com relações de poder. O poder de definir a identidade e de marcar a diferença não pode ser separado das relações mais amplas de poder (p. 81). 
A identidade precisa ser compreendida como uma forma de pertencimento, de identificação com um grupo social, com uma filosofia ou com outras formas de organização em que o discurso se faça presente (Danielewicz, 2001; Ferreira, 2014; Hall, 2009; Moita Lopes, 2003; Norton, 2000). O discurso desempenha papel seminal no processo de construção de identidades, isso porque, nas diferentes práticas sociais, assumimos distintos papéis que, inevitavelmente, transitam entre discursos de diferente natureza.

Para Moita Lopes (2003), torna-se impossível dissociar o discurso da produção social da identidade, uma vez que ambos, discurso e identidade, são construtos gerados a partir das relações sociais: "(...) todo discurso provém de alguém que tem suas marcas identitárias específicas que o localizam na sua vida social e que o posicionam no discurso de um modo singular, assim como seus interlocutores" (p. 19). Em se tratando do discurso como gerador e mantenedor de identidades, e segundo afirma Hall (2009), é porque as identidades sociais "são construídas dentro e não fora do discurso que nós precisamos compreendê-las como produzidas em locais históricos e institucionais específicos, no interior de formações e práticas discursivas específicas, por estratégias e iniciativas específicas" (p. 109).

Para Danielewicz (2001), por sua natureza ideológica e por serem impactados pelas ingerências das relações de poder existentes nas diferentes práticas sociais, os discursos representam poderosos condutores e transmissores de valores e ideologias, pelo que nunca são produções isentas de intencionalidade. Dessa forma, toda a história sobre identidade resulta de um enfrentamento da identidade e da diferença - enfrentamento, portanto, fundado nas relações de poder.

Norton (2000), Danielewicz (2001), Botía et al. (2005), Moita Lopes (2003) e Silva (2009) asseveram que a transição entre diferentes discursos sobre um determinado grupo social ou profissão influencia sobremaneira a forma como os sujeitos irão reconhecer-se ou recusar-se a reconhecer-se em certas identidades. Em outras palavras, a interpelação de questões sociais, políticas e culturais na manutenção de certos sentidos sobre a identidade profissional pode contribuir tanto para o sentido de pertencimento quanto de diferença, ou seja, de contraste sobre si e sobre o grupo social em questão (Jenlink, 2014). Nessa perspectiva, construímos identidades múltiplas ao longo de nossa existência, uma vez que, por exemplo, ao assumirmos o papel 
social de professora, não deixamos de ser mulheres, de pertencer a determinada etnia, de ter determinada condição social.

Em linhas gerais, conforme Pimenta (1998), Telles (2002) e Nóvoa (2013), a identidade profissional vem sendo tecida sociohistoricamente por meio das interações sociais, das oportunidades formativas, das experiências de vida, das trajetórias escolares - portanto, assume dimensões distintas ao longo da história de cada um. Isso significa que a percepção que construímos sobre a profissão professor está sempre em trânsito, em construção; por essa razão, a realização de uma pesquisa narrativa com foco na rememoração de trajetórias escolares pode contribuir para o maior entendimento sobre como os futuros professores se compreendem e a profissão, e sobre isso discutimos na próxima seção.

\section{Experiências de aprendizagem: entre as identidades e a diferença}

Ao longo de nossas trajetórias escolares, experienciamos diferentes práticas pedagógicas realizadas por professores e professoras com distintas concepções de educação e de ensino de Língua Inglesa. Em maior ou menor escala, participamos de aulas de Língua Inglesa compostas por atividades estruturalistas com base na memorização e na tradução, aulas dinâmicas repletas de atividades em grupo e materiais didáticos diversificados, aulas ditas tradicionais e centradas na figura do professor, entre outros modelos de aula a que fomos expostos durante a nossa escolarização. Embora as experiências como alunos de Língua Inglesa possam variar de um aluno para outro, o que parece regular é que essas experiências ficam registradas nas trajetórias dos sujeitos, que, conforme avançam na escolarização, vão compondo um repertório tanto de experiências quanto de discursos sobre o que é ser professor. Para alguns de nós, assim como para parte dos pibidianos sujeitos da pesquisa, o estudo da Língua Inglesa só se tornou possível via educação básica; portanto, as primeiras percepções sobre ensinar e aprender língua estrangeira tomou como referência a experiência vivida na escola. Para outros, porém, o acesso a aulas de Língua Inglesa em institutos de idioma ou cursos livres efetivou-se como alternativa para o estudo do idioma, dado que, indubitavelmente, amplia as expectativas dos alunos acerca da aprendizagem da língua. 
Em nossa pesquisa narrativa realizada para o doutorado em Letras (Baladeli, 2015), a proposição de narrativas autobiográficas como um dos instrumentos de pesquisa mostrou-se eficiente para gerar dados sobre as memórias que os sujeitos tinham das aulas de Língua Inglesa na escola e suas percepções sobre elas.

$\mathrm{Na}$ narrativa autobiográfica $\mathrm{n} .02$, exemplo trazido neste artigo, revelamos discursos de seis dos dezessete pibidianos sujeitos da pesquisa. A título de sistematização, optamos por discutir separadamente os discursos que na narrativa autobiográfica foram identificados como memórias positivas e memórias negativas dos pibidianos sobre suas aulas de Língua Inglesa na escola.

As narrativas autobiográficas foram propostas a partir de algumas questões norteadoras. Optámos por não delimitar quantidade de linhas; assim, o pibidiano poderia, a seu critério, responder separadamente às questões ou integrá-las em uma narração apenas. As questões apresentadas aos pibidianos para a elaboração da narrativa autobiográfica n.02 foram:

- Quais suas memórias das aulas de Língua Inglesa na escola?

- Defina um(a) bom/boa professor(a) de inglês. Você teve esse modelo de professor(a) em sua vida escolar? Comente.

- Esses modelos de professor(a) influencia(ra)m ou não sua postura hoje como professor(a) em formação inicial?

Discutimos primeiramente as narrativas autobiográficas de três pibidianos referentes às memórias positivas das aulas de Língua Inglesa na educação básica. O primeiro discurso é o de Laura. A pibidiana tinha vinte e cinco anos, estava no Pibid da Universidade Beta há pelo menos um ano, estudou em instituto de idiomas por cinco anos e cursou a educação básica integralmente na rede pública de ensino.

\section{Narrativa n. 02}

As memórias de aulas de Língua Inglesa na escola são em sua maioria positivas, professores dinâmicos e responsáveis. Um bom professor de inglês é um professor preocupado com os alunos, tinha todas essas características, aprendi muito com ela e, mais importante, despertou meu interesse em procurar mais. Os professores influenciam tanto os bons exemplos quanto os exemplos não tão positivos, que também auxiliam no que não devemos fazer. (pibidiana Laura) [destacado nosso] 
A trajetória escolar de Laura revelou uma visão positiva dos modelos de aula de Língua Inglesa que teve - "professores dinâmicos e responsáveis"-, o que também se estende quando descreve uma de suas professoras, que, na percepção da pibidiana, tinha práticas pedagógicas atrativas e dinâmicas que favoreceram em sua aprendizagem do idioma. A identificação de Laura com essa professora de Língua Inglesa revelou que, mesmo estando na licenciatura, espaço formal de profissionalização do professor, sua referência de aula de Língua Inglesa continuou sendo aquela realizada pela professora da educação básica. Laura reconheceu as contribuições das aulas de Inglês que teve na escola e assumiu o aspecto da identificação com seus professores como fundamento para a projeção de si na profissão professor.

Laura também destacou que o incentivo da professora de Inglês concretizou-se como o legado mais significativo do que a própria aprendizagem do idioma em si, o que revelou a identificação da pibidiana com as práticas pedagógicas de sua professora. A esse respeito, Hall (2009) explica que a construção da identificação ocorre "[...] a partir do reconhecimento de alguma origem comum, ou de características que são partilhadas com outros grupos ou pessoas, ou ainda a partir de um mesmo ideal" (p.106). Ainda nessa sequência, foi possível interpretar que a identificação das pibidianas com suas professoras resultou em um acordo tácito, em que elas, as pibidianas, ao aceitarem determinado conjunto de condutas e valores observados em suas professoras, começaram a compartilhar da mesma concepção de educação, concepção de ensino de Língua Inglesa, assumindo assim identificação positiva com a profissão.

O segundo discurso é o de Andréia. A pibidiana tinha quarenta e dois anos, participava do Pibid há pelo menos um ano e na ocasião era acadêmica de Letras Português e Inglês da Universidade Alfa. Realizou sua formação escolar somente em instituições públicas e não frequentou instituto de idiomas.

Sem dúvida, o professor é uma grande influência na vida do aluno. Tenho memórias muito boas das aulas que tive de inglês e me recordo muito bem de todas as professoras que tive e sei que elas influenciaram muito na minha escolha para este curso. Para mim, as professoras que eu tive sempre foram as mais criativas e animadas da escola desde o $5^{\circ}$ ano até o ensino médio. E isso faz com que meu interesse aumentasse cada vez mais. (pibidiana Andréia) [destacado nosso] 
A pibidiana assumiu o discurso da identificação com suas professoras de Inglês ao rememorar suas práticas pedagógicas, que, uma vez caracterizadas como positivas, a fizeram considerá-las como referência de boas professoras. Segundo Andréia, o fato de ter tido uma experiência agradável de estudo de Língua Inglesa na escola em razão das práticas pedagógicas de professoras que considerava boas professoras influenciou na escolha pelo curso de licenciatura. Andréia atribui a suas professoras o mérito por também ter escolhido ser professora: "(...) as professoras que eu tive sempre foram as mais criativas e animadas da escola desde o $5^{\circ}$ ano até 0 ensino médio. E isso faz com que meu interesse aumentasse cada vez mais".

O terceiro discurso é o de Caroline. A pibidiana tinha vinte e dois anos, estava no $2^{\circ}$ ano de Letras Português-Inglês da Universidade Alfa e na ocasião participava há seis meses do Pibid. Estudou Língua Inglesa durante três anos em instituto de idiomas e a educação básica foi integralmente cursada em escolas públicas.

Lembro pouco das aulas de inglês no ensino básico, mas lembro que os professores eram empenhados em ensinar da melhor maneira, mas sem recursos adequados e até o conhecimento mesmo, limitavam tanto aluno quanto professor. O uso da língua era escasso e tinha desinteresse por parte dos alunos. Um bom professor é aquele que tem o DOM de ensinar, ele não precisa ser dominador do assunto para ensiná-lo, apenas tem que ter o 'feeling' de despertar no aluno o interesse e a segurança de sua autoridade, que é diferente do autoritarismo, que mostra que o professor é despreparado para cumprir a função que se propôs. Tive bons professores que conseguiram despertar o desejo pelo saber, não só na língua inglesa, mas também em todas as outras matérias. Exemplos de profissionais e, principalmente, pessoas, as quais guardo em minha memória e pretendo seguir os bons exemplos. (pibidiana Caroline) [destacado nosso]

Embora Caroline tenha ilustrado que se identifica com seus professores, sobretudo por serem incentivadores da aprendizagem de Inglês, na sequência discorre sobre as condições de trabalho vivenciadas por suas professoras e problematiza a profissão à luz dos desafios que observa na escola. Na percepção de Caroline, a pouca proficiência de seus professores somada ao descaso por parte dos alunos para com o estudo do idioma ilustraram o cenário da escola pública como um espaço complexo para atuação profissional. A pibidiana ainda revelou que a sua concepção de bom professor perpassa características mais relacionadas com "saber ensinar" do que com o domínio do idioma que ensina; assim, para Caroline, para ser 
professor é preciso ter uma habilidade inata que autorize o professor a exercer a profissão com maestria.

Laura, Andréia e Caroline compartilharam da percepção de que seus professores de Inglês eram bons, considerando os critérios que utilizaram para tal caracterização, e que todos eles se destacaram por incentivar o estudo e a aprendizagem da Língua Inglesa, aspectos fundamentais de um bom professor segundo as pibidianas. O que as narrativas das três pibidianas revelaram é que as boas aulas de Língua Inglesa na escola e a atuação de seus professores tiveram relativo impacto na forma como elas se projetam na profissão professor.

Os próximos discursos referem-se a uma percepção negativa das aulas de Língua Inglesa. O quarto discurso é o de Ofélia. A pibidiana tinha vinte anos, era acadêmica do curso de Letras Inglês da Universidade Beta, participava do Pibid há um ano e estudou a maior parte da educação básica em escola pública, tendo frequentado cursos de idiomas por quatro anos.

Minhas memórias em relação à língua inglesa não são muito boas, pois de todos os anos que tive inglês lembro que uma professora somente era 'boa', a que tive aula na $5^{a}$ série (quem sabe ela não fosse tão 'boa', quem sabe seja porque foi minha $1^{a}$ professora de inglês). Para mim, um bom professor de Língua Inglesa é aquele que envolve seus alunos com a língua, que os cativa com aspectos e cultura da língua que interessem a eles, que consiga fazer ligações da língua inglesa com seus contextos sociais. Até hoje, só conheci modelos de professor assim em cursinho, me influenciaram de forma com que eu me sinta animada; mesmo com todos os problemas vistos em escola, ainda assim me sinto animada a ser uma profissional assim. (pibidiana Ofélia) [destacado nosso]

A pibidiana Ofélia destacou que ao professor de Língua Inglesa cabe uma prática pedagógica intercultural, ou seja, para além do mero ensino enciclopedista e estruturalista do idioma. Embora seu discurso tenha sido iniciado pela narração de sua trajetória a partir de uma professora da $5^{\mathrm{a}}$ série (primeiro ano de ensino formal da Língua Inglesa na educação básica no Brasil; atualmente esta fase é denominada $6^{\circ}$ ano), na sequência, pondera a sua própria menção a esta professora com o argumento de que talvez à época a considerasse uma boa professora por ter sido a primeira professora de Língua Inglesa que teve. Ofélia também adotou a lógica da diferença para categorizar seus professores. Para ela, no espaço dos cursos privados teve a oportunidade de conhecer professores bons: "só conheci modelos de 
professor assim em cursinho"; já no contexto da escola, sua percepção de bom/mau professor é interpelada pelo reconhecimento das condições de trabalho em que se encontram os professores: "mesmo com todos os problemas vistos em escola". Assim, para Ofélia, embora bons professores possam ser encontrados em cursos pagos, na escola as condições estruturais e mesmo da carreira do professor interferem no desempenho dos professores e também na aprendizagem do aluno, o que parece indicar que a pibidiana passa a assumir a posição, no discurso, de professora, e não mais de aluna, visto que problematiza a profissão no contexto atual.

O quinto discurso é o de Bianca. A pibidiana tinha dezoito anos, estava há pelo menos seis meses no Pibid da Universidade Alfa, estudou por quatro anos em instituto de idiomas e cursou a educação básica integralmente na rede pública de ensino.

Hoje de manhã eu estava observando a prática da professora supervisora com a sequência didática [...], eu comentei com uma pibidiana: "nossa, se eu tivesse aulas deste jeito na minha época, eu teria aproveitado muito". E é exatamente isso. Eu sou bem traumatizada com meus professores de Língua Inglesa do ensino fundamental e médio. Tem coisas que eu nunca esqueço como: um aluno perguntou para a professora como se falava 'ele faltou', então a professora respondeu "he isn't here" e eu escrevi no meu caderno 'riisantirir'. Eu nunca esqueço disso! Outra situação no $2^{\circ}$ ano do ensino médio: a professora passou uma atividade de 'ache o ladrão' e, simplesmente, não explicou nada, nada mesmo. Entregou a folha e se virem! Nunca esqueço disso, eu me senti muito constrangida, incapaz mesmo. Esses antigos professores me inspiraram para não ser igual eles. Eu sei se eu for lecionar hoje, no $2^{\circ}$ ano de Letras, farei dez vezes melhor que eles. Pelo menos irei explicar, trazer atividades interativas para que os alunos se sintam satisfeitos com o aprendizado de LI. (pibidiana Bianca) [destacado nosso]

Ao recuperar suas memórias das aulas de Língua Inglesa, Bianca revelou a concepção de professor que tinha na época, a de um sujeito detentor absoluto do conhecimento, e, por conseguinte, a percepção de assimetria entre professor e aluno, embasada pela relação de poder. Para tanto, rememorou um episódio em que se sentiu constrangida em sala de aula devido ao que - ela acredita - se concretizou como um trauma adquirido nas aulas de Língua Inglesa. Embora critique a forma como as aulas eram conduzidas na escola - "(...) a professora passou uma atividade de 'ache o ladrão' e, simplesmente, não explicou nada, nada mesmo. Entregou a folha e se virem!"-, ao final da narrativa autobiográfica a pibidiana modalizou suas 
críticas a partir do momento em que considerou as condições objetivas em que muitos professores de Língua Inglesa se encontram. A partir daqui, pareceu refletir sobre o trabalho do professor ocupando não mais o papel de ex-aluna, mas, sim, de professora em formação inicial que, no contexto do Pibid, tem tido a oportunidade de discutir os desafios do ensino de Inglês na escola pública. Ao mesmo tempo em que considerou o conhecimento lingüístico de seus professores (dominavam a língua), Bianca pareceu indicar que faltava neles motivação, o que na percepção dela indicava a carência de um pressuposto básico para o exercício da docência. Da mesma forma que Ofélia, Bianca também evidenciou que seu processo de (re)construção identitária se valeu da lógica da identidade e diferença. Para ela, ao interpretar que vivenciou práticas pedagógicas negativas, aprendeu também o que e como não fazer em sala de aula como professora, ou seja, o que não deve ser reproduzido; "Esses antigos professores me inspiraram para não ser igual a eles".

O sexto discurso é o de Juliano. O pibidiano tinha vinte e três anos, estava há pelo menos cinco meses no Pibid da Universidade Beta, estudou um ano em instituto de idioma e cursou a educação básica majoritariamente na rede privada de ensino.

O inglês que tive, tanto em escola pública como particular, foi extremamente abaixo do satisfatório. A matéria permanecia a mesma por diversos anos e a didática era muito mecânica. Não tive modelos de professores na vida escolar. Para mim, um professor bom consegue conciliar ensino com atividades lúdicas, que divirtam e ensinem ao mesmo tempo. Professores exemplares incentivam a formação de novos professores, através da motivação pela alegria de ensinar. (pibidiano Juliano) [destacado nosso]

As memórias das aulas de Inglês do pibidiano foram construídas, a princípio, sob uma perspectiva negativa, isso porque não observou contribuições ou mesmo algum avanço em sua aprendizagem do idioma: "A matéria permanecia a mesma por diversos anos e a didática era muito mecânica". A sensação de pouco ou nenhum progresso ao longo do estudo dos conteúdos das aulas de Inglês fez com que Juliano não construísse sentidos positivos para sua trajetória de aprendizagem do idioma na escola. A percepção negativa das aulas de Língua Inglesa não é privilégio apenas da escola pública, visto que, para o pibidiano, também na escola privada, espaço em que teve o privilégio de estudar, o descontentamento com as aulas se fez 
presente, evidenciando a co-existência do sentimento de expectativas e de frustração em relação às aulas. O bom professor de Língua Inglesa, segundo Juliano, seria aquele que conseguisse utilizar-se pedagogicamente do lúdico; fazendo isso, serviria de exemplo para seus alunos: "Professores exemplares incentivam a formação de novos professores, através da motivação pela alegria de ensinar".

Ofélia, Bianca e Juliano ilustraram certas expectativas em relação ao que consideravam ser um bom professor de Inglês: aquele que, além de realizar práticas pedagógicas dinâmicas, cotejando os aspectos culturais e o lúdico em suas práticas, deveria considerar também as relações interpessoais com os alunos - o que denominamos de dimensão afetiva. Mesmo nas narrativas em que se observou pouca ou nenhuma identificação dos pibidianos com seus professores de Língua Inglesa da educação básica, cabe destacar o lugar privilegiado que as memórias das trajetórias escolares têm ocupado no processo de (re)construção identitária dos pibidianos.

Segundo Baladeli (2014), o espaço do Pibid tem auxiliado na maior integração de futuros professores com a realidade do ensino e aprendizagem da Língua Inglesa no contexto da escola pública (ver também Jordão et al., 2013; Retorta \& Bork, 2014). Dessa forma, quanto mais familiarizados estiverem com este campo de atuação, maiores serão os subsídios para decidirem ou não seguir na profissão professor. Mais do que incentivar a formação de professores, as ações do Pibid têm trazido à tona questões que perpassam os modelos de formação de professores praticados nos cursos de licenciatura e a necessidade de se repensar quais discursos estão sendo reproduzidos sobre o ensino e a aprendizagem de Língua Inglesa na escola.

Longe de propormos uma análise maniqueísta com base na classificação do bom e do mau professor de Língua Inglesa, nossa análise das trajetórias escolares a partir do recorte de narrativas autobiográficas de seis pibidianos objetivou evidenciar o processo histórico de (re)construção da identidade profissional que se vale, inclusive, das primeiras experiências como alunos de Inglês na escola. Dessa forma, a discussão sobre os percursos de construção das identidades como alunos de Inglês e como professores em formação inicial está diretamente relacionada com a área de formação de professores, isso porque, ao ressignificarem suas próprias trajetórias, os pibidianos estão tendo subsídios para melhor compreender a si mesmos e a profissão professor. 


\section{Considerações finais}

A realização de uma pesquisa narrativa acerca do processo de (re)construção da identidade profissional ilustrou que os atos de (re)memorar as trajetórias escolares e de problematizá-las à luz dos novos sentidos sobre a profissão precisam ser considerados como provisórios, uma vez que, nos limiares da história de vida e profissional, novas práticas sociais continuarão sendo pano de fundo para novos sentidos sobre o sujeito professor e sua profissão.

A participação no Pibid ao longo da graduação foi apontada por todos os pibidianos como um diferencial formativo significativo, tanto no que se refere à aprendizagem de aspectos teórico-metodológicos atinentes ao ensino de Língua Inglesa, quanto ao desenvolvimento de uma postura científica mediante a participação em eventos e publicações científicas.

Conforme Jenlink (2014), nossas identidades são (re)escritas ao longo de nossas trajetórias de vida e escolar; por essa razão, a pesquisadora advoga que ao processo de (re)construção das identidades profissionais de professores estão subjacentes as influências de nossos projetos de vida. A autora adota a metáfora do palimpsesto para ilustrar que os discursos de identidade podem ser escritos, reescritos e ressignificados ao longo de nossa história.

O processo de (re)construção da identidade profissional não se limita ao tempo e espaço da licenciatura ou mesmo de participação no Pibid, uma vez que a identidade vem sendo tecida desde a escola nas primeiras experiências e expectativas construídas na condição de estudantes, nas relações com os professores, na escolha pelo curso de Letras e demais práticas sociais em que se inserem os pibidianos. Por essa razão, os sentidos identificados nos discursos das narrativas autobiográficas dos pibidianos apresentam-se como temporários, haja vista que os sentidos estão sempre oscilando conforme o contexto de produção. Em outras palavras, esses pibidianos poderão vivenciar ainda novos desafios como professores em formação inicial, dado que indubitavelmente influenciará a (re)construção de suas identidades profissionais, tema tão relevante para as discussões sobre formação de professores. 


\section{Referências}

Baladeli, A. P. D. (2014). O Pibid na formação inicial do professor de Língua Inglesa: Em busca do paraíso perdido. Revista E-scrita do curso de Letras da Uniabeu,5(2), 240-250.

Baladeli, A.P.D. (2015). Narrativas de identidade do professor de Língua Inglesa: o legado do Pibid. Tese de Doutoramento em Letras - Linguagem e Sociedade, Universidade Estadual do Oeste do Paraná - UNIOESTE. Brasil.

Bolívar, A. (2002). Profissão professor: O itinerário profissional e a construção da escola. Bauru, SP: EDUSC.

Botía, A. B., Cruz, M. F., \& Ruiz, E. M. (2005). Investigar la identidad profesional del profesorado: Una triangulación secuencial. FQS Fórum Qualitative Social Research, 6(1), 1-26.

Clandinin, D. J., \& Connelly, F. M. (2011). Pesquisa narrativa: Experiências e história na pesquisa qualitativa. Uberlândia, MG: Edufu.

Danielewicz, J. (2001). Teaching selves: Identity, pedagogy, and teacher education. US: State University of New York Press.

Dubar, C. (2005). A socialização: Construção das identidades sociais e profissionais. São Paulo: Martins Fontes.

Ferreira, A. J. (2014). Identidades sociais de raça, gênero, sexualidade e classe nos livros didáticos de língua estrangeira na perspectiva da Linguística Aplicada. In A. J. Ferreira (Org.), As políticas do livro didático e identidades sociais de raça, gênero, sexualidade e classe em livros didáticos (pp. 91-120). Campinas, SP: Pontes.

Gatti, B. A. (1996). Os professores e suas identidades: O desvelamento da heterogeneidade. Cadernos de Pesquisa, 98, 85-90.

Hall, S. (2009). Quem precisa de identidade? In T. T. Silva, S. Hall, \& K. Woodward (Orgs.), Identidade e diferença: A perspectiva dos estudos culturais $\left(9 .^{a} \mathrm{ed} ., \mathrm{pp}\right.$. 103-133). Petrópolis, RJ: Vozes.

Jenlink, P. M. (2014). Learning our identity as teacher: A palimpsest writ large in life. In P. M. Jenlink (Ed.), Teacher identity and the struggle for recognition: Meeting the challenges of diverse society (pp. 247-257). US: R\&L Education.

Jordão, C., Edmundo, E., Gomes, H., Albuquerque, M., Galor, A., Rosa, A., ...Trinkel, M. (2013). O PIBID-UFPR nas aulas de Inglês: Divisor de águas e formador de marés. Campinas, SP: Pontes Editores.

Moita Lopes, L. P. (2003). Socioconstrucionismo: Discurso e identidades sociais. In L. P. Moita Lopes (Org.), Discurso de identidades: Discurso como espaço de construção de gênero, sexualidade, raça, idade e profissão na escola e na família (pp. 13-38). Campinas, SP: Mercado de Letras.

Norton, B. (2000). Identity and language learning: Gender, ethnicity and education change. Harlow, England: Pearson Ed. Limited.

Nóvoa, A. (2013). Os professores e o "novo" espaço público da educação. In M. Tardiff \& C. Lessard, (Orgs.), O ofício de professor: História, perspectiva e desafios internacionais (pp. 217-234). Petrópolis, RJ: Vozes. 
Pimenta, S. G. (1998). Formação de professores: Saberes da docência e identidade do professor. In I. Fazenda (Org.), Didática e interdisciplinaridade (7. ${ }^{a}$ ed., pp. 161178). Campinas, SP: Papirus.

Retorta, M. S., \& Bork, A. V. B. (2014). Experiências de formação de professores de Línguas e o PIBID: Contornos, cores e matizes. Signum: Estudos da Linguagem, 17(2), 413-419.

Silva, T. T. (2009). A produção social da identidade e da diferença. In T. T. Silva, S. Hall, \& K. Woodward (Orgs.), Identidade e diferença: A perspectiva dos estudos culturais (9. ${ }^{\mathrm{a}}$ ed., pp. 73-102). Petrópolis, RJ: Vozes.

Street, B. V. (1995). Literacy in theory and practice. Cambridge: Cambridge University Press.

Telles, J. A. (2002). A trajetória narrativa: Histórias sobre a prática pedagógica e a formação de professores de línguas. In T. Gimenez (Org.), Trajetórias na formação de professores de Línguas (pp. 15-38). Londrina: Editora da UEL.

\section{Legislação}

Ministério da Educação (2013). Portaria n. ${ }^{\circ}$ 096, de 18 de julho de 2013. Aprova o Regulamento do Programa Institucional de Bolsa de Iniciação à Docência (Pibid). 
TEACHER IDENTITIES AND DIFFERENCE IN THE DISCOURSE OF PRE-SERVICE ENGLISH LANGUAGE TEACHERS

\begin{abstract}
In this paper we discuss the concepts of teacher identities and difference based on a selection of data collected during a narrative research study. This research was carried out with a group of six pre-service English teachers who integrated the Pibid, a Brazilian program for teacher professionalization. The aim was to identify meanings for the teacher profession in the discourses of these teachers from two public universities in Brazil. The analysis was supported by the theoretical framework of New Literacy Studies and identity studies focused on the influence of the school trajectories on their professional identities. In general terms it was possible to observe the relation between school trajectories and the meanings constructed by the pre-service English teachers about the teacher profession. The discourses exposed that professional identities are being constantly negotiated and that the opportunity to engage pre-service students in a program such as Pibid has allowed the group to reflect about themselves as teachers and about the teacher profession.
\end{abstract}

Keywords

Teacher identities; Difference; Pibid; Teacher profession

\title{
LAS IDENTIDADES DOCENTES Y LA DIFERENCIA EN EL DISCURSO DE LOS PROFESORES DE INGLÉS EN LA FORMACIÓN INICIAL
}

\section{Resumen}

En este artículo discutimos los conceptos de identidades docentes y de la diferencia desde una selección de datos de una investigación narrativa. La investigación fue conducida con un grupo de profesores de Inglés en la 
formación inicial que eran participantes en el Pibid, un programa brasileño de profesionalización docente. El objetivo de la investigación fue identificar en los discursos dos profesores de duas universidades publicas brasileñas cual los significados están construyendo acerca de la profesion docente. El análisis fue basado en los nuevos estudios de alfabetización y en los estudios de identidad con énfasis en la influencia de las experiencias escolares en la construción de las identidades docentes de estos seis profesores. En términos generales fue posible observar en el discurso de los seis profesores la relación entre las experiencias escolares y los sentidos que construyen do que significa ser profesor de Inglés. Los discursos ainda indicaron que las identidades docentes están en contínua negociación y que la participación en programas como Pibid ha favorecido la reflexión del grupo sobre sí mismo y también sobre la profesion docente.

Palabras clave

Identitidades docentes; Diferencia; Pibid; Profesión docente

Recebido em abril/2015

Aceite para publicação em setembro/2015

i Imaginar - Grupo de Pesquisa sobre Imaginário, Educação e Formação de Professores, Universidade Estadual do Oeste do Paraná (Unioeste), Brasil.

ii Programa de Pós-Graduação em Letras - Linguagem e Sociedade, Universidade Estadual do Oeste do Paraná (Unioeste), Brasil.

iii Programa de Linguagem, Identidade e Subjetividade, Universidade Estadual de Ponta Grossa (UEPG), Brasil.

Toda a correspondência relativa a este artigo deve ser enviada para: Ana Paula Domingos Baladeli, Cascavel-PR, Brasil. Rua Universitária, 1619, Bairro Universitário. Colegiado do curso de Pedagogia. CEP: 85819-110. E-mail: apdbaladeli@gmail.com 